Achieving equity through 'gender autonomy': the challenges for vocational education and training (VET) policy and practice

Karen Evans

Institute of Education, University of London

First published in the Journal of Vocational Education and Training, 2006

Volume 58 pp $393-408$

ISSN 1363-6820 


\title{
Achieving equity through 'gender autonomy': the challenges for VET policy and practice
}

\begin{abstract}
This paper is based on research carried out in an EU Fifth Framework project on 'Gender and Qualification'. The research partners from five European countries investigated the impact of gender segregation in European labour markets on vocational education and training, with particular regard to competences and qualifications. The research explored the part played by gender in the vocational education and training experiences of (i) young adults entering specific occupations in child care, electrical engineering and food preparation/service (ii) adults changing occupations.
\end{abstract}

Empirical data from 244 interviews, observations in VET institutes and at workplaces and content analyses of job advertisements, curricula, brochures and other sources confirmed that "gender still matters" from the viewpoint of the individual, in their experiences of skill formation and attribution, occupational choice and personal development. But empirical data also revealed "gender blindness" in VET institutes and at workplaces when it comes to considering, positively and constructively, the continuing significance of gender differences in vocational education and training and in work. This paper undertakes a secondary analysis of key findings and identifies the need to create the conditions 
for strengthening of 'gender autonomy' as the conclusion of most relevance to the UK VET and lifelong learning policy context. 


\section{Introduction}

'Gender and Qualification' was a project of the Fifth European Framework Programme. Subtitled 'Transcending gendering features of key qualifications for improving options for career choice and enhancing human resource potential', the project aimed to investigate the impact of the gender segregation in European labour markets on vocational education and training, with special regard to 'key' competences. The project, coordinated by Heidegger and Kampmeier (Germany), was undertaken by a partnership of teams from England (Evans, Hoffmann, Saxby-Smith), Finland (led by Heikkinen), Greece (led by Patiniotis), and Portugal (led by Figuera).

As well as working cross-culturally, a particular challenge of the project was to attempt to bring together two 'segregated' perspectives. Gender studies have tended to regard issues of competence and qualification as minor considerations in researching sources of inequality in the labour market and VET, yet these are major foci for much VET research. While studies by Heikkinen(1996), Kleinan and Mayer (1996) and, in the UK, by researchers such as Cockburn (1988), Bates and Riseborough (1993), Skeggs (1997) and Brine (1999) have focused respectively on historical and social processes in the gendering of VET and employment practices, there has been a tendency to ignore or marginalize gender studies within the field of 'vocational pedagogy', particularly where the latter has long established traditions. As Niemeyer has expressed it, from a German standpoint : 'work that has explicitly been elaborated on the gender relations in VET remains marginal if not excluded from the mainstream of research' (Niemeyer 2004).

Empirical data from 244 interviews, observations in 10 VET institutes and associated 
workplaces and extensive content analyses of job advertisements, curricula, brochures and other sources confirmed that "gender still matters" in view of the individual, in experiences of skill formation and attribution, occupational choice and personal development. But empirical data also revealed "gender blindness" in VET institutes and at workplaces when it comes to considering, positively and constructively, gender differences for vocational education and training and for work.

This paper is based on a secondary analysis by the author of the findings of this project, which has led to the development of the concept of gender autonomy. This concept is used as lens through which attempts to transcend the gendering features of 'key competences' and improve options for career choice may be viewed and analysed.

'Key' competences have become part of the language of policy throughout the EU. While these labels and the ideas they encapsulate are highly contested, and ascribed many different meanings, they are linked by the argument that they embody capabilities that can and should be deployed by everybody in or seeking to enter the labour market. Yet there is a gendered discourse in these areas. For example, the interpersonal competences that are often cited as 'key' in this sense are also often held to be 'female skills'. The origins of these attributions are varied. Personality and actions of the individuals, the cultural background, the structure of vocational education and training and the structure of the labour market are all important, but above all gender stereotypes, part of the day to day lived experiences of individuals, have a more determining influence on ways in which the relative competences and skills of men and women are recognised and ascribed. 
This conclusion was based on the interview-statements of both men and women in gender "typical" occupations; of "exceptional cases" (women and men in gender-untypical occupations); and of other key informants, including tutors, supervisors and employers, who were asked about competences of men and women in gender-untypical occupations. Men and women often choose gender-typical occupations because of social expectations or social "normalcy" and consequently develop or are trained in gender-typical competences. Gendered key competences thus become intensified by gender-typical occupations and gender segregation is reconstructed as occupational tasks and cultures influence ways in which 'key competences' are recognised and deployed.

The following sections review and exemplify the findings that led to this conclusion, with a view to elaborating the concept of gender autonomy as a useful means for understanding, and then intervening in, the macro-, meso- and micro factors that shape gendered experience.

\section{Key competences - what are they?}

For the project, operating trans-nationally, it was difficult to arrive at a common working concept of key competences. This contested domain is further complicated by the longstanding trans-national confusions about the relationships between competences and the continental European concept of 'qualification' in the context of occupations. Nijhof and Streumer (1998) have attempted to review the multiple definitions of and concepts circulating, concluding in summary that key competences are designed to help to prepare young persons for life, for an occupation, for employability and for citizenship (Nijhof 1998) and are based on the affirmative assumption that they are necessary and useful (p20). Uncritical use of the concept ignores or treats as unproblematic the informal 
contexts and everyday situations that shape these 'competences'. Differences in experience can both reflect and reinforce social inequalities of gender, race and social class. In the case of gender, they are part of a 'gender regime', rooted as a network of norms, regulations and principles in the structure of social practices (see Connell 2002 p 139). They are manifested specifically in dominant constructions of 'masculinities' and 'femininities' and the differential value ascribed to competences gained through paid and unpaid forms of work and different types of occupations, these in turn reflecting the relative power of different social groups to claim status and rewards for their work.

A reflexive approach that sees gender regimes as dynamic rather than static led us to the version of the concept of key competences we came to employ trans-nationally. This emphasised the compound mix of inner attributes and abilities of the person which are not clearly visible but which can be made effective when situations in which the person is expected, or has an opportunity, to perform are favourable (see also Evans et al 2004). Key competences, understood in this way, are developed reflexively through experiences in a range of life and work environments. There is potential to support people towards the achievement of 'critical insight' (see Roth 1971, Stromquist 2006) into themselves and into the limits and possibilities afforded by their everyday situations in paid and unpaid forms of work.

\section{Methods}

The international research was conducted using hermeneutical and empirical methods. Documentary and literature analysis covered: 
- Gendered structures of respective national VET systems and labour markets, together with a synthesis of commonalities and structural differences of the participating countries;

- VET-related gender studies including historical, cultural and economic conditions and research on career orientation and gender; and

- The current national/international discourses and debates on key competences.

For the empirical part of the investigation, the following were carried out:

- Observation of classes and working practices in 21 programmes in 10 vocational schools (Further Education Colleges in England), in child care /nursery nursing (female typical), electrical engineering (male typical) and food service (mixed gender) and in up to five work sites associated with each of these programmes in each country;

- Interviews with 100 participants in the above programmes, including trainers and employers;

- Studies of 17 'exceptional' cases (male nursery workers, female electricians);

- 127 interviews with adult 'occupational changers; and

- Content analyses of advertisements, brochures and information materials in the chosen occupational areas.

While the research was confined to particular localities in each of the countries, this multimethod approach enabled essential localised analysis (see Weiner 1997) of how interests and competences are formed and how they relate to VET experiences and practices in situ. 
In each country evidence of the wider 'social regularities' in male and female participation available though occupational/labour market data and other surveys was used to confirm or problematize aspects of the findings, which were then combined in systematic crossnational comparison.

\section{'Typical' cases}

Occupational choices of people in 'gender typical' occupations were influenced by the different social and cultural contexts of the partner countries but also demonstrated gendered features that transcended national boundaries. The majority of interviewees said they had chosen their occupation largely through the influence of family and relatives, yet those choices were very different for men and women. There was evidence of characteristics and competences being ascribed to gender in all three areas ${ }^{1}$. In children's nurseries, female workers were ascribed characteristics of being more tender and patient, better able to help children with basic hygiene, feeding and clothing babies. Trainers and female nursery nurses in all countries themselves considered males less sensitive and to have less aptitude in connecting socially with the children and parents. Often such skills are deemed to come more 'naturally' to women. This is consistent with the observation of Noon and Blyton (2002) that so-called female skills are viewed as 'natural' - leading to a further view that they are not deserving of the same level of reward as skills that have to be acquired and learnt, such as technical skills.

\footnotetext{
${ }^{1}$ While competences are 'classed' and raced' as well as 'gendered', gendering of competences has been the particular focus of this study.
} 
While these patterns of attribution were very visible in the work environments of electrical engineering and nurseries, divisions of labour according to ascribed characteristics was also apparent in the gender mixed environments of food preparation and restaurants. Men were give the 'heavier ' tasks of arranging chairs and tables while the decorative, ornamental tasks tended to fall to the women - although this division of labour was certainly not always in line with personal preferences. In our analysis, then, gendered key competences are key competences that regarded as 'typical' for men or women because they are more often performed by, ascribed to or expected from men rather than women, or vice versa.

Despite this, in response to questions such as 'do men make better electricians than women?' and 'can men be good children's nursery workers?' two-thirds of interviewees considered that there are no inherent differences between the sexes in abilities to work successfully in any given occupation. One third of interviewees perceived clear differences between the sexes in their occupational abilities. However within this second group, most also held the view that things were changing, with only three percent thinking that only men or women can do certain occupations successfully.

The findings showed that the pervasiveness of gender in everyday work relations contributed, paradoxically, to its invisibility to the eyes of many VET practitioners, most of who claimed that they treated everyone as an individual irrespective of gender (see Hoffmann, 2004). In many cases they regarded gender as 'no longer an issue'. 
Two ways of uncovering the effects of gender were employed. The first was to investigate the experiences of the 'exceptional cases', people who have made atypical career choices of children's nursery work (for men) and electrical engineering (for women). The second was to examine the experiences of adults moving into the labour market after periods of interruption in their occupational life.

\section{The 'exceptional' cases}

Finding male nursery workers and female engineers proved more difficult in some countries than in others. For example in Portugal, Greece and the UK, very few men choose the low paid and low status occupations of nursery workers or child care assistants, while increasing (although still small) numbers of women are entering engineering. In Germany the reverse is found: there are more male children's nursery workers than female electricians. Kampmeier (2004) argues that low pay and status is not such a disincentive in the German context and most men entering this area aim for career development through training. Engineering, however, is a very high status job in Germany with a high competition for training places and jobs, and very few women put themselves forward for this area of work.

The views of people working in gender typical occupations could be compared with those from the "exceptional" cases. This provided very valuable insights since those in atypical occupations have a "near image" of the situation, they know about gender differences from their own experiences: They are also able to compare these with "far images", the public opinion of gendered key competencies. They are aware of the parts played by gender in the social practices of VET institutions and at the workplace. They also recognise, to a much 
greater extent than the "typical cases" the variety of ways in which gender-"typical" behaviour and gender-"typical" personal competencies can be observed during training and at the work place. It was found that these "exceptional" cases indeed manifested different configurations of prior experience as well as personal competence when compared with the "typical" cases.

Most research cases who had made exceptional career choices had developed non-typical interests during their childhood, and had developed particular patterns of 'key competences' through this process. These were further developed during their training as female electricians and male nursery nurses. For example, in the UK study, ${ }^{2}$ the two female electricians had both been encouraged by their fathers earlier in life. Liz, for example, had been encouraged by her father, who was a construction engineer. Within the family, Liz helped her father with the D-I-Y and fixing the family car. She and her sister were also interested in Formula 1 racing, and they would go as a family to watch it. Liz said that as a child she preferred to play with Lego ${ }^{\circledR}$ and to 'try to assemble and dismantle things', rather than play with 'girlie toys'.

Similarly Jane, when asked why she had chosen electronics, said that it was related to the interest she had from childhood in how things worked.

'I had always been interested in puzzles, making things fit and work ... From when I was a child, I was always involved with PCs because my father built them when they were first brought out, and I knew how to programme them, no problem. My friends were into radios and we used to take them apart and change the frequencies ... I looked back and thought I did get 
enjoyment from building and making things and proving why things work; the logic. It's like a challenge to me ... That's why I thought it was something to try. I'd get enjoyment from the course and hopefully be able to get a job out of it.'

These two exceptional cases are consistent with the findings of Newton (1987, p 195), whose research into women engineers showed that they were quite likely to be the daughters of engineers, and that the father's attitudes were important influences in the occupational choice process. Women who chose engineering as a career were also significantly more likely to have played with unconventional (boys) toys in their childhood.

Family members had also been involved in the choices of the male 'nursery nurses'. Simon's father, for example, had helped by obtaining information about the course knowing his son's interest in working with children, and had supported and encouraged his son's choice. For Daniel, working with children had been a long-standing interest. During his teens, he would help out on play schemes in holidays and enjoyed being with younger groups of children because 'they needed me, they looked up to me and that was quite nice.' His sister had also had a baby, and having a 'lovely little niece' had also contributed to his developing interest in working with very young children. At 18 years old he was offered a job helping to run a play scheme, and then enrolled on the course. For Michael, though, this was a second choice of occupational field. He would have preferred a job with 'power' and status, but illness and disability had made this difficult for him. His parents had been

\footnotetext{
${ }^{2}$ See Evans K \& Saxby-Smith (2003) for fuller accounts of the UK cases.
} 
supportive if worried about the demands of children's work on their son, and he had become enthusiastic about and highly committed to the work.

The exceptional cases reported a variety of ways in which they were treated differently from their gender counterparts, on their work sites and in training programmes. Their views differed from the attitudes and views of their trainers. Trainers thought that female electrician trainees were tidier and more industrious than men, but sometimes less strong in logical thinking and technological creativity - areas that Jane identified as her particular strengths.

\footnotetext{
'Being able to work on your own; if something isn't working properly, to be able to fault find ... The equipment in my eyes is very easy to use. It's all very logical. Somebody would need to have a logical mind to work the equipment, but really it just like learning to type. Maths is important, as there are a lot of formulas involved. The main thing is that you need to very precise.'
}

Jane explained that it was not necessary to be strong because the engineers are not expected to carry the instruments themselves. When asked whether she thought the problem-solving skills that she had emphasised were more associated with males or females, she seemed puzzled by the question and said 'I don't think that gender has anything to do with it'.

Male nursery workers were often expected to concentrate on playing with the children, particularly during outdoor activities, and were often called on for everyday practical tasks of a physical or technical kind. Their female counterparts more often chose - or were urged 
- to do the basic caring. The ways in which they reacted to these expectations varied.

Daniel initially disagreed that he was asked to do 'male' things:

'No, I don't think there is anything that I am asked to do because I am male. Everybody takes it equally. If it is music and movement, or changing the children when they are potty training, we have all taken turns at that.'

It became evident, however that it was Daniel's attitude and input that had contributed to the equal sharing of tasks. For example, when asked to unblock a drain, he said ' $\mathrm{OK}$, you do it like this. Next time, you can do it.' Similarly, he would question why he should be asked to carry heavy boxes while his female colleagues stood and watched. 'Now they won't ask me to do anything like that unless they are asking someone else as well.' His female colleagues had notions of what tasks were appropriate for males, but Daniel challenged these notions and resisted the pressure to behave in accordance with gender stereotypes.

The part played by gender in the experiences of the exceptional cases contrasted starkly with the significant number of people interviewed who felt that gender was no longer an issue. The 'exceptional' cases felt that they had to overcome rather strong reservations and sometimes prejudices on the part of employers and colleagues, but also of family and friends. Liz, for example, had to withstand 'stupid' remarks from boys, and their disbelief that she was studying engineering. Her strategy for managing this was to demonstrate that she was interested in the same things they were; cars for example. In this way, she felt that she gained acceptance. Her female friends thought that she was 'brave'. They didn't 
understand her interest in technical things, but there was no evidence in her comments that she experienced any discouragement from them.

In Simon's case, the attitudes of the parents of the children he was caring for, towards a young male in a childcare role, caused him difficulties. In his social life, he and the other exceptional cases would present what they were doing as something different to avoid mockery and disbelief e.g. 'nursery officer' or 'professional training in child care': 'Some people said, "What are you doing childcare for? Are you gay? I face that quite a lot. When I was doing the childcare taster course at the $6^{\text {th }}$ Form College, we had to make a soft toy using a sewing machine, which is fair enough. The sewing machine was placed opposite the rugby pitch with the lads playing rugby. I don't think the tutors realised what they had done. That made it quite a difficult couple of months. I got a lot of negative there, but I'm bigger than that. People can say what they want. I don't really care.'

This illustrates a particular problem experienced by all the exceptional cases, that they struggle to assert their gender identity in the face of the prejudices they encounter. They wished to assert their gender identity as well as an occupational identity and the older ones had already achieved that.

Being on the course had affected Simon's identity as a male. He said that his female peers regarded him as 'one of the girls'. He often felt isolated and had experienced problems finding a girlfriend. 
Liz felt that there was no difference between males and females in their performance on the engineering course, but she also tried to preserve her female identity. She said that she 'wears make-up, perfume and jewellery, and her hair is always tidy'. In contrast to the boys, her boiler suit is much cleaner, her writing is neater, and her car is tidier. In her words she 'does not want to turn into a bloke'. Interestingly, she also said that she 'could never go out with a boy who was a nursery nurse'.

The evidence showed that overcoming prejudices in atypical training and employment requires particular resilience and much determination. Jane talked of some of the pressures of being the only female in the training programme. While she believed that there is 'not really a difference between girls and boys', she felt that she continually had to prove herself. She said that she had to work very hard and everyone noticed when she did something wrong. Yet the tutors felt that there was no differentiation according to gender - males and females were treated equally and any differences stemmed from individual abilities and personalities.

In discussing their ambitions and longer term views of their prospects, gender influences surfaced even more strongly for the exceptional cases. For females, any difficulties faced were seen as part of a process of buying into the better pay and prospects of an engineering career. Yet the interviews with male engineering trainers showed the further gender segregation they would encounter. Female engineers were often seen as offering the people skills that marketing departments were looking for, a tendency also identified in Faulkner's (2006) research into Genders in/of Engineering. Computer-Aided Design was also identified as a field with openings for women (see also DTI 2002). Liz mentioned that some of her female friends worked in CAD companies 'but they only do simple designs'. 
She had her sights set on a future as a design engineer - a field identified as having a relatively small gender pay gap.

For the males entering child care, who were buying into a low-status, low paid occupational area, the difficulties they faced in acceptance of their chosen roles were compounded by the potentially disempowering and limiting nature of the work. Daniel said that nursery nurses are treated 'like skivvies' by the parents and the job is low paid:

'They don't treat us with the actual knowledge we have got. We are just playing with the children ... They don't see the background work.'

With few opportunities for promotion, many men decide not to stay as nursery workers (see also Cameron et al 1999). For Simon, his desire to work with young children was combined with aspirations and plans to move as quickly as possible into a professional job within the field. This contrasted with the aspirations of the female students who said that they wanted to become nannies and nursery nurses. Daniel felt strongly that childcare was a professional job, but that society did not see it like that. His awareness of this led him to conceal that he was a nursery nurse in social situations with people who were in jobs which he felt had high status. His slight ambivalence about the extent to which gender mattered in his day to day activities disappeared when the discussion turned to his ambitions. $\mathrm{He}$ wanted to be a Head of Unit, had applied for two posts without success and saw the absence of no male heads of units in his present company as indicative of gender discrimination. 
Michael, said he had done the 'socially unthinkable' but found his vocation in child care, which was 'fulfilling, exciting and challenging'. The interviews with male nursery workers generally showed them to be resilient and highly committed, with a determination to overcome negative affects of gendered attitudes and behaviour.

Given the difficulties identified it is no wonder that some young people leave atypical training at an early stage because they find the learning and working environments intolerable. However those who succeed appear to be more conscious of their occupational choice and thus sometimes more engaged. Recommendations should aim at supporting them, while also creating the conditions to enable more people to 'stay the course' without having to display the exceptional resilience of the survivors.

The UK cases used illustratively here were paralleled in the other country studies, showing shared features of experiences of 'exceptional cases' that transcend national boundaries, although it should be noted, with Heikkinen (1996) that the cultural embeddedness of expectations does vary considerably between settings and cultural groups at a more detailed level.

\section{Key competences and interrupted occupational careers}

The search for evidence of the extent to which gendered perceptions of competences affect occupational lives was extended to adults by examining cases of men and women 'changing direction' in occupation, and spending time out of the labour market. Data from 127 interviews conducted with adults in the international project confirmed that in almost 
all cases there was a clear division of labour within the home and that the women's occupational choices were circumscribed by the need to fit their occupational roles around their domestic responsibilities.

In the UK study 20 biographical interviews were carried out, 15 with men and women who had returned to the labour market after taking time out of work for family reasons or a period of unemployment, and five with people whose wish to change occupation arose primarily while in work. ${ }^{3}$

Most of these interviewees expressed satisfaction with their area of work. In the UK cases, Anita, the only person in the sample in a professional job, continued with her commitment to teaching. Marianne was 'reasonably happy' with her work as a bookkeeper in her husband's company and had 'always enjoyed numbers and lists'. Sue and Kirsten wanted to work with children and in addition to being a part time school road crossing attendant, Sue was also involved in a range of voluntary work, including special needs teaching. Similarly, Di was working as a school meals assistant and was also helping with toddler groups and a Night Shelter management committee. It was evident that these women possessed a wide range of skills that were being deployed in areas outside their paid employment, which was often classified as low skill and low status.

Of the five who had returned to the same field of employment after a period out of the workforce the three women, all of whom were involved in office work, appeared very clear about their occupational choices, and all said that they had wished to return to full-time office work as soon as possible. The two men, who were both in traditionally male jobs, 
plumbing and metal machining, had both got their jobs through friends. David was working part-time due to child-care responsibilities as a single parent.

An analysis of the abilities that the interviewees said they had developed and mastered while out of the labour market revealed a mix of methodological and social competences, together with personal attributes that they felt had been acquired or strengthened:

- Males - Budgeting, organisation

- Females - Organisation, negotiating, interpersonal skills, flexibility, listening, cooking, planning, budgeting, being assertive, being patient, caring, time-management

Among the occupational changers for whom a change in direction was not primarily prompted by an extended career break, the key competences mentioned by all the females in some form included:

- being able to take on a range of varied activities

- interpersonal competences

- $\quad$ ability to influence people positively

- questioning and learning competences

From the viewpoint of those returning to work from family breaks, competences acquired outside paid employment were not seen as having much relevance or importance to the workplace apart from jobs which encompassed caring and domestic roles. The women working with children could see the value of their skills. Those who were engaged in work unrelated to caring, particularly the males, could not see the relevance at all.

\footnotetext{
${ }^{3}$ A fuller account of cases is given in Evans and Saxby-Smith, 2003
} 
The data raise questions as to whether these kinds of competences are themselves gendered, and seem to lend some support to the issues raised by Hoffmann (2001 pp 4041) in relation to the 'persistent and notorious term, female skills', citing popular media sources which assert that 'female skills' including empathy, caring, 'listening' and time management are becoming increasingly essential in the workplace, with men exhorted to get in touch with 'their feminine side' (see, for example 'The Future is Female' BBC Panorama).

If we accept that these types of competences are generic, and valuable to the process of transfer between different types of occupations, then these competences also need to be seen as gender neutral. Ascribing gendered features to these competences contributes to the maintenance of gender segregation in the labour market. The idea that the recognition of key competences could be used increase career options thus has to be seen in the wider context of the social processes which influence the ways in which the relative competences and skills of men and women are recognised, ascribed and valued.

\section{Gender autonomy}

Gender autonomy refers to the extent to which people, regardless of gender, are able to develop their chosen career path (whether in paid or unpaid occupations, or a mixture of the two) according to individual predilections, without penalty or disadvantage accruing from that choice. This applies both to material disadvantage and social approval/disapproval . It is a significant outcome of the Gender and Qualification project that supporting gender autonomy should be at the centre of improvements regarding gender segregation in the labour market, as an alternative (or at least a complementary) strategy to seeking ways of equalising the numbers of people from each sex in each occupation. This does not lead to a deficit model conclusion that people should become more resilient and 
determined to succeed, while the barriers remain. It leads instead to some insights into the kinds of support needed for people who want to exercise their gender autonomy by going into atypical fields, while enabling the many women and men who want to do so to exercise gendered preferences with neither penalties nor unfair advantages.

At the 'macro' level, how far have our respective societies progressed in relation to the goal of gender autonomy? If our aim is to counter gender stereotyping, we have also to take care not to stereotype countries. The study 'Gender Autonomy in Europe'- An Imprecise Revolution' by Singh (1998), employed a battery of indicators relevant to gender autonomy to produce a classification that countered some popular stereotypes. Nordic women were shown as experiencing above-average gender segregation. Yet protection of high unionisation of part-time work and the public sector as well as social benefits were shown to enable both women and men to exercise gendered preferences without penalties or unfair advantages, thus providing 'a sound basis for gender autonomy'. (p150).

Southern countries, particularly Greece and Portugal were classified by Singh as having high progressive potential, through modernising processes, with new laws being enacted in line with the latest European guidelines. Both countries also have strong non-formal sectors which potentially allow for high levels of role sharing between men and women, simultaneously supporting the family and favouring the concept of the welfare state. Germany and England were classified as conservative, with change taking place slowly. This, according to Singh, reflects the belief, in the case of the UK, that it is not the state's role to provide redistributive services. In Germany the barriers in the way of gender autonomy were held to stem from beliefs that egalitarianism is at best of secondary interest to stability. Impediments and entrenched barriers (such as lack of adequate affordable pre- 
school child-care in England and relatively weak legal bases for equal opportunities (UK and Germany) slow the pace of change in women's experiences in the labour market despite strong rises in female educational participation and achievements.

The evidence from the partner countries in the present study reflected these characteristics. Yet a reflexive approach to these 'gender regimes' also highlights the spaces for transformative change (see also Stromquist 2006), with a balance to be struck between working for gender autonomy at the level of the individual and local environment and pressing for improvements in social conditions.

\section{Advancing gender autonomy}

The furthering of gender autonomy has, then, to be considered at three levels:

- The individual level;

- The level of VET systems and recruitment practices in the labour market; and

- The macro-level of socio-political features of the society.

The evidence concerning gendered perceptions of competences enables us to link previously segregated discourses of gender studies and VET. We have asked to what extent competences could play a role in gender autonomy and might become part of the solution as well as part of the problem.

On the individual level, we conclude that people should be supported in developing relevant competences ( the complex mix of inner attributes and abilities identified earlier) connected to self-assurance, that is

- to try to become aware of one's own competences beyond usual prejudices, 
- to call in question the conventional perceptions of what is a male or female occupation,

- to dare to make "atypical" occupational choices,

- to develop perseverance in order not to give up at an early stage of an atypical career.

On the level of VET systems and recruitment practices it is important to provide encouragement to all people, but especially to support those who intend or have decided to choose an occupation which is atypical for their sex,. This requires the use of pedagogical approaches which support the development of competences in the direction of the critical insights and critical engagement in their VET and work environments, as part of dialectical, or 'shaping' processes.

In VET (including training in companies) this means actions:

- to counteract the processes which render gender invisible to practitioners, including 'tiredness' with gender issues and conceptions, at least in the UK, that the problem has already been solved.

- to give opportunities for people to work in gender-mixed classes,

- to provide mentoring by people who have themselves made an atypical choice,

- to be more aware of prejudices regarding 'gender -typical' key competences.

These recommendations are addressed to VET practitioners and personnel managers responsible for recruitment as micro-policies are particularly important. However, policy making on a meso-level has to provide the framework conditions for these practices to be successful. This includes training for teachers, trainers and personnel managers. 
In addition, the 'macro' societal conditions are of utmost importance, for example setting wages according to gender equity, and making provisions for childcare, parental leave and part time work. If the aim is to move towards greater gender autonomy, there is a need to reduce the gender related penalties and barriers for those who make particular occupational choices. These may be the gender-related penalties of low pay for caring occupations or the penalties/barriers of hostile working environments for people entering gender atypical occupations. The systemic features can change but are slow to do so, the conservative forces are great and the state of social development uneven. Yet as the power relations in gender regimes are subject to conflicting social interests, formation and dissolving of accepted categories and the re-structuring of institutionalized relations (Connell 2002), the advancement of gender autonomy requires an understanding of how gender operates at all social levels. This is also consistent with developments in post-structural feminist theory that aim to reconnect work on identities with wider social and political environments in more complex ways (see Heikkinen (2004) and Stromquist (2006) for further discussion).

\section{What is it possible to change through VET?}

What can we in VET actively do to encourage and support change, while recognising that what VET can do will always be very partial?. Social structures take much longer to change, but what influences can be exerted by VET practitioners to support change in the desired direction? The outcomes of the Genderqual project have pointed to the relevance of considering, through the concept of "gender autonomy", how highlighting key competences and improving learning environments can contribute to improving options for career choice and enhancing human potential. It has shown:

- that overcoming barriers in atypical training and employment requires particular resilience and much determination. 
- that the exceptional cases who survived the challenges are the tip of the iceberg. Drop out in the early stages occurs quite frequently for people who are less resilient or who find particular situations and attitudes intolerable.

- that this does not lead to a deficit conclusion that people should become more resilient and determined to succeed without tacking barriers; it leads instead to some insights into the kinds of support needed for individuals who want to exercise their gender autonomy by going into atypical fields.

- that people who survived in atypical occupational situations found different ways to assert their gender identity.

- their experiences also reflect the power and social position of the gendered occupation they are entering, a process highlighted by the double disempowerment experienced by males entering low status female-typical occupations.

These insights lead to recommendations that:

1. Use of key competences as tools for policy and practice cannot advance the cause of gender autonomy alone, without building gender issues into vocational pedagogy - 'doing gender'.

2. Much more mixed gender teaching across occupational areas is required to explore and challenge assumptions about competences, to consider gender identity issues and provide identity support.

3. Supportive networks need to be created of practitioners who are gender sensitive and committed to change. For example, in the same way that colleges would not dream of sending a trainee to a placement that had poor health and safety practices, VET institutions could take steps to ensure that placements are 
only used which can demonstrate good gender practices. This can be done in a non-bureaucratic way by establishing networks of practitioners with common aims and goals.

4. Steps be taken to counter the gender tiredness of teacher and trainers who are not already committed to change in this field, with approaches that are fresh (eg based on identity and work and evidence informed practice) and feasible (eg networks-based).

5. Recognize that working for policy change in the framework conditions at a societal level takes longer, but should take place alongside and in parallel with creation of such networks.

VET can only exercise partial influence on the forces and factors that restrict gender autonomy. It cannot by itself change macro-social forces or the early experiences of individuals. But is the space that VET does have being used fully? The aim is to expand awareness of the spaces which can be used by VET practitioners to advance the cause of gender autonomy. In summary, we need to find ways within the structures and practices of VET to make the 'exceptional' less exceptional in the future, by reducing the penalties (social, economic and emotional) for those who exercise their gender autonomy in new directions.

\section{References}

BBC Videos (1996) The Future is Female (London, BBC)

Bates, I. and Riseborough, G. eds (1993) Youth and Inequality, (Buckingham, Open University Press). 
Brine, J. (1999) Under-educating women: globalising inequality (Buckingham, Open University Press).

Cameron, C., Moss, P\& Owen, C (1999) Men in the nursery: Gender and caring work (London, Sage Publications)

Cockburn, C. (1988) The gendering of jobs: workplace relations and the reproduction of sex segregation in S.Walby (ed) Gender and Segregation at Work, Milton Keynes: Open University Press

Connell R.W. (2002) Gender. (Malden, Blackwell).

DTI (2002) SET FAIR: Report on Women in Science, Engineering and Technology, (London, Department of Trade and Industry).

Evans, K. \& Niemeyer, B. (2004) Reconnection: Countering Social Exclusion through Situated Learning. (Dordrecht, Kluwer).

Evans, K., Kersh, N., and Kontiainen, S. (2004) Recognition of Tacit Skills: sustaining learning outcomes in adult learning and work re-entry. International Journal of Training and Development Vol 8 No 1 pp 54 - 72.

Evans, K. \& Saxby-Smith, S. (2003) Genderqual project: Third National Report, BIAT. (Flensburg, University of Flensburg)

Faulkner,W. Gender in/of Engineering: research report. (Swindon, ESRC)

Heidegger, G., Adolph, G., Laske, G. (1997) Gestaltungorientierte Innovation in der Berufsschule (Innovation of vocational schools according to the shaping approach.) (Bremen, Donat)

Heidegger, G., Kampmeier, A. Evans K, Figueira, Heikkinen, Patiniotis, N. (2004) Gender and Qualification: Transcending gendering features of key qualifications for improving options for career choice and enhancing human resource potential. EU 
Research on Social Sciences and Humanities Report (Brussels, European Commission).

Heikkinen, A.(ed) (1996) Gendered History of Vocational Education - European Comparisons (Hameenlinna, University of Tampere).

Heikkinen, A. (2004) Culturally embedded actor-based approach to gendered core competences in Heidegger et al Gender and Qualification pp37-47.

Hoffmann, B (2004) The importance of exceptional cases for the project in Heiddeger et al, Gender and Qualification, Brussels: European Commission, pp59-67.

Kampmeier, A. (2004) Gender and Qualification: Scientific description of the project results and methodology in Heiddeger et al pp 35-50.

Kleinan, E. and Mayer, C. (Eds) Erziehung und Bildung des weiblichen Geschlechts. (Weinham, Deutscher Studies Verlag).

Newton, P (1987)`Who Becomes and Engineer? Social, Psychological Antecedents of Non-Traditional Career Choice' in A.Spencer \& D.Podmore In a Man's World: Essays on Women in Male-Dominated Professions.London: Tavistock Publications

Niemeyer, B. (2004) Gender and Qualification: Theoretical Background in Heidegger, G. et al Gender and Qualification pp22-34

Nijhof W.J. (1998) Qualifying for the Future In Nijhof W.J. and Struemer, J. (1998) Key Qualifications in Work and Education, (Dordrecht, Kluwer Academic Publishers) Nijhof W.J. and Struemer, J. (1998) Key Qualifications in Work and Education. (Dordrecht, Kluwer Academic Publishers)

Noon M. and Blyton P. (2002) The Realities of Work. (Basingstoke, Palgrave) Roth, H (1971) Padagogische Anthropologie (Pedagogical Anthropology). (Hannover, Schroedel.) 
Saxby-Smith, S (2001) Tacit Skills and Key Competences (TACITKEY) National Report, Flensburg; BIAT University of Flensburg

Singh R (1998) Gender Autonomy in Western Europe: An Imprecise Revolution (Basingstoke, Macmillan Press)

Skeggs, B. (1997) Formations of Class and Gender (London, Sage)

Stromquist, N. P.(2006) Gender, education and the possibility of transformative knowledge, COMPARE, Vol 36, No 2 pp 145-162.

UK Resource Centre for Women in SET (2006) www.setwomenresource.org.uk

Weiner, G. (1997) New Era or Old Times: class, gender and education. British Educational Research Association Annual Conference. September 11-14 1997: University of York Williams, C (1989) Gender Differences At Work: Women and Men inNon-Traditional Occupations. (Berkeley, University of California Press). 